\title{
Desafios da gestão ambiental na transferência de água entre bacias: estudo de caso da integração do rio São Francisco, Brasil
}

\section{Environmental management challenges in water transfer between \\ Data de entrada: basins: case study of integration in the São Francisco river, Brazil $12 / 03 / 2020$ \\ Data de aprovação: $12 / 08 / 2020$}

Hidaiane Fayga Matias Caldas ${ }^{1}$ * Antônio Italcy de Oliveira Júnior ${ }^{1}$ |

Davi Tadeu Borges Marwell ${ }^{2}$ | Maria do Carmo Martins Sobral'

DOI: https://doi.org/10.36659/dae.2022.010

\section{ORCID ID}

Caldas HFM (D) https://orcid.org/0000-0001-8332-0015

Oliveira Júnior Al (D) https://orcid.org/0000-0002-8297-5068
Marwell DTB (D) https://orcid.org/0000-0002-5950-5316

Sobral MCM (iD https://orcid.org/0000-0001-8945-1606

\section{Resumo}

A transferência de água entre bacias tem sido uma solução adotada para mitigar os efeitos da distribuição desigual dos recursos hídricos. Este artigo trata de uma análise sobre os principais desafios em relação à gestão ambiental do Projeto de integração do rio São Francisco com as bacias do Nordeste Setentrional, situado em região semiárida do Brasil. O presente trabalho foi desenvolvido a partir de análises bibliográficas sobre o assunto e documentos oficiais acerca do empreendimento, fornecidos pelo governo do Brasil. A partir da compilação das informações obtidas nas diversas bibliografias, foi possível identificar quatro principais desafios da gestão ambiental no âmbito do projeto: o conflito entre os setores energético e de irrigação, a operação do sistema de captação e distribuição da água ao longo dos canais, os impactos não abordados no estudo de impacto ambiental e as consequências do armazenamento da água em reservatórios. $O$ enfrentamento das questões levantadas passa pela dinamização da matriz energética do país, pela adoção de modernas tecnologias de instrumentação e corpo técnico qualificado para operar o sistema para viabilizar a cobrança pelo uso das águas, por maior controle e fiscalização das técnicas de manejo na irrigação na áreas, investimento em infraestrutura de saneamento básico, gestão do uso do solo na bacia, além do uso de dispositivos que diminuam a evaporação nos reservatórios. A consideração dos desafios da gestão ambiental identificados neste trabalho pode colaborar para o atendimento aos objetivos e à sustentabilidade do projeto de integração do rio São Francisco.

Palavras-chave: Gestão ambiental. Desafios. Transferências de água. Integração do Rio São Francisco.

\section{Abstract}

The interbasin water transfers have been a solution adopted to mitigate the effects of unequal distribution of water resources. This article deals with an analysis of the main challenges related to the environmental management of the integration project of the São Francisco river with the north-east basins located in the semiarid region of Brazil. The present work was developed from bibliographic analysis on the subject and official documents about the enterprise provided by the Brazilian government. Based on the compilation of the information obtained in the var-

\footnotetext{
${ }^{1}$ Universidade Federal de Pernambuco - Recife - Pernambuco - Brasil.

2 Ministério do Desenvolvimento Regional - Brasília - Distrito Federal - Brasil.

* Autora correspondente: hidaianecaldasagmail.com.
} 
ious bibliographies, it was possible to identify four main environmental management challenges within the scope of the project: the conflict between the energy and irrigation sectors, the operation of the water abstraction and distribution system along the channels, the impacts not addressed in the environmental impact study and the consequences of water storage in reservoirs. The confrontation of the issues raised involves the dynamization of the country's energy matrix, the adoption of modern instrumentation technologies and qualified technical staff to operate the system to enable the collection of water use, greater control and control of irrigation management techniques in areas, investment in basic sanitation infrastructure, management of land use in the basin, and the use of devices that reduce evaporation in reservoirs. The consideration of the challenges of environmental management identified in this work can contribute to meeting the objectives and sustainability of the integration project of São Francisco River.

Keywords: Environmental management. Challenges. Water transfers. Integration of São Francisco river.

\section{INTRODUÇÃO}

Segundo Neves e Cardoso (2009), a água doce é um recurso finito e é imprescindível para o bemestar do ser humano e para a manutenção dos ecossistemas. Logo, com o aumento da população, a industrialização, a intensificação de atividades agrícolas e outras transformações sociais e econômicas, há um aumento da demanda per capita para a utilização da água e das restrições de oferta pelo aumento da poluição hídrica, gerando escassez e conflitos, mesmo em países e regiões onde a água pode parecer abundante, como no Brasil.

O desequilíbrio entre as demandas e as disponibilidades hídricas regionais constitui um dos principais problemas de alocação e distribuição de água que os sistemas de gerenciamento de recursos hídricos necessitam resolver. Para tanto, pode-se tomar como exemplo a região Nordeste do Brasil, que concentra $28 \%$ da população do país e, em contrapartida, tem apenas $3 \%$ dos recursos hídricos brasileiros (AZEVEDO et. al., 2005).

Nesse contexto, dentre as diversas propostas que foram estudadas para aumentar a disponibilidade hídrica na região, o governo considerou como melhor opção transferir parte das águas do rio São Francisco para a região Nordeste, dando origem, assim, ao Projeto de Integração do rio
São Francisco com as Bacias Hidrográficas do Nordeste Setentrional (PISF), realizado pelo Ministério da Integração Nacional.

O PISF é uma grande obra de infraestrutura para transferência de água entre bacias e, como tal, envolve notáveis desafios pelo fato de abranger possíveis realidades socioeconômicas e ambientais diferentes, além de considerações políticas distintas. Além disso, especificamente, não se pode deixar de descartar as implicações positivas e negativas em termos de impactos ambientais, sociais, culturais e econômicos na bacia doadora, na bacia receptora e ao longo do traçado do caminho que ligará as duas bacias, a depender das metas a serem alcançadas e das alternativas escolhidas (RAJABU, 2008).

O planejamento e a gestão ineficientes, associados aos fatores externos não controláveis, como as mudanças climáticas, podem inviabilizar o sucesso desse projeto. Dessa forma, apesar de as obras do PISF estarem em andamento, depois de anos de atrasos e diversas polêmicas ambientais, econômicas e sociais, ainda existem questões a serem expostas e debatidas entre os diversos atores envolvidos no projeto, incluindo a comunidade diretamente afetada, a fim de que seja promovido um gerenciamento de modo a obter o máximo de benefícios. 
Diante do exposto, este trabalho apresenta uma visão dos desafios encontrados na gestão ambiental da transferência de águas entre bacias, aplicada ao caso do Projeto de Integração do rio São Francisco com as Bacias Hidrográficas do Nordeste Setentrional, no Brasil. São abordadas brevemente algumas experiências internacionais das quais podem ser extraídas lições referentes aos aspectos determinantes dos sucessos e insucessos de projetos desse tipo, além de apresentadas sugestões sobre como aprimorar, de maneira geral, a gestão e o planejamento desse projeto que tem grande importância para o desenvolvimento da região.

\section{TRANSFERÊNCIA DE ÁGUA ENTRE BACIAS}

O problema da escassez de água para múltiplos usos ocorre em várias regiões do mundo, mesmo em países com abundância geral de recursos hídricos. Em certas áreas, a demanda facilmente excede a oferta, suscitando situações de conflito pelo domínio desse bem indispensável e estratégico. $\mathrm{Na}$ busca de formas de solucionar as dificuldades decorrentes da insuficiência de água, as transferências de água entre bacias hidrográficas se apresentam como uma alternativa controversa devido aos grandes impactos gerados, mas que vem sendo adotada por diversos países ao longo da história.

Dentre os principais impactos ambientais ocasionados pelas transferências de água entre bacias estão implicações físicas, químicas, hidrológicas, biológicas e ecológicas nos ecossistemas afetados (ZHUANG, 2016; ZENG et al., 2015; FORNARELLI et al., 2013), além de uma variedade de questões não ambientais, incluindo política, economia, sociedade e cultura local (ZHAO et al., 2017). Com o advento da legislação ambiental, a implementação desses projetos é condicionada à liberação de uma série de licenças, que visam garantir a segurança do meio ambiente envolvido. A natureza complexa dos grandes projetos gera incertezas e riscos significativos, e esse conjunto de normas ambientais é a base para o desenvolvimento da gestão eficiente desses grandes empreendimentos.

Zhuang (2016) listou os projetos mundialmente renomados de transferência de água entre bacias, espalhados por países como EUA, Canadá, os que compõem a ex-União Soviética, Índia, Paquistão e China.

A população chinesa sente os efeitos da distribuição desigual dos recursos hídricos no seu território, onde o norte do país padece com uma escassez cada vez mais grave na última década em virtude da sua intensa industrialização e do crescimento populacional, enquanto o sul sofre com inundações frequentes (ZHAO et al., 2017; ZHUANG, 2016; HE et al., 2014). A fim de equilibrar esse cenário, foi proposto o "SouthNorth Water Diversion Project - SNWDP”, um megaprojeto que visa transferir a água da bacia do rio Yangtze para a planície norte da China, incluindo três rotas principais de transferência de água: leste, central e oeste, além de conectar quatro grandes rios - Yangtze, Huai, Amarelo e Hai (RPC, 2016). A implementação do projeto teve início em 2002, com conclusão prevista para 2050, com um volume estimado de água a ser transferida de 44,8 bilhões de $\mathrm{m}^{3}$ por ano, beneficiando mais de 300 milhões de pessoas (ZHAO et al., 2017; ZHUANG, 2016).

Com a finalidade de atender a vários usos, como demandas urbanas, industriais e agrícolas, o SNWDP é um projeto de engenharia complicado e gigantesco que compreende múltiplos empreendimentos. Em suas fases projetual, de construção e operação, o projeto enfrentou uma série de desafios e dificuldades técnicas, além de complexidades políticas pelo fato de as cabeceiras de muitos rios internacionais fluírem dessa região, afetando potencialmente o uso da água nos pa- 
íses vizinhos (HE et al., 2014). No tocante aos impactos ambientais, o SNWDP provocou grande controvérsia por não ser considerado um sistema viável de abastecimento de água devido a sua ampla demanda de energia, que atualmente é suprida em grande parte por combustíveis fósseis, ademais dos impactos potenciais nas áreas doadoras da água, como a potencial escassez nas fontes e intrusão de água salgada no estuário do Rio Yangtze (LI et al., 2016).

Os grandes projetos localizados no oeste dos Estados Unidos são em sua maioria de usos múltiplos, e contribuem para o desenvolvimento da irrigação artificial na região. Um dos maiores e mais complexos realizados no país é o "Colorado-Big Thompson Project". O projeto desvia cerca de 320 milhões de metros cúbicos de água por ano das nascentes do rio Colorado, na costa oeste, até o rio Big Thompson, um afluente do rio South Platte na costa leste do estado do Colorado. A construção do projeto começou na represa Green Mountain em novembro de 1938 e foi concluída em 1959 com a construção da Usina Big Thompson. Embora tenha sido concebido inicialmente para fins de irrigação agrícola, atualmente atende múltiplas demandas, como abastecimento municipal e industrial, geração de energia elétrica e recreação (US Bureau of Reclamation, 2019). Atualmente, há conflitos entre os usos de recreação e prioridade ao armazenamento para abastecer a população, além de outros quanto aos direitos sobre as águas do Colorado em relação ao Canadá, onde elas nascem. Os principais impactos foram as grandes inundações que ocorreram na parte inferior do rio Colorado acarretando mudança do regime hidrológico e da biodiversidade aquática, além do problema com a intrusão salina na foz do delta do rio Colorado (NEVES e CARDOSO, 2009).

Na Austrália, o projeto "Snowy Mountains Hydroelectric Scheme-SMHS" foi desenvolvido para geração de energia hidrelétrica, irrigação de terras agrícolas e também para dar apoio ao abastecimento de água da região sudeste do país, com uma infraestrutura que inclui 16 reservatórios, sete usinas hidrelétricas, uma estação de bombeamento, $145 \mathrm{~km}$ de túneis e $80 \mathrm{~km}$ de aquedutos, construída entre 1949 e 1974 com capacidade para transportar 1,13 bilhão de $\mathrm{m}^{3}$ de água por ano (ZHUANG, 2016; ANDRADE et al., 2011; WWF, 2007). Apesar de seus benefícios, a falha dos planejadores em avaliar exaustivamente as questões ambientais e potenciais resultados negativos levou a impactos importantes, como a redução do fluxo de água e irrigação natural da bacia ribeirinha e erosão a jusante na bacia receptora (ANDRADE et al., 2011), além do assoreamento do canal do rio, invasão de árvores exóticas, intrusão de água salgada no estuário e perda de populações de peixes migratórios (WWF, 2007).

\section{PROJETO DE INTEGRAÇÃO DO RIO SÃO FRANCISCO}

Nos últimos anos foram implementadas grandes obras de infraestrutura no Brasil com o intuito de promover o desenvolvimento da nação e das regiões que constituem o país (HENKES, 2014). Em escala regional, a transposição do rio São Francisco é um exemplo situado no semiárido e agreste do Nordeste brasileiro. A obra visa captar água em dois eixos a partir do rio São Francisco, que é um dos poucos rios perenes que cortam a região Nordeste do Brasil. Em seguida, transferir a água captada para bacias situadas nos quatros estados da região denominada Nordeste Setentrional (Ceará, Pernambuco, Paraíba e Rio Grande do Norte).

De acordo com o Relatório de Impactos Ambientais-RIMA do projeto (BRASIL, 2004), o mesmo visa proporcionar água à população (cerca de 12 milhões de habitantes) situada em 390 municípios dos quatros estados da região, bem como 
a grandes centros de abastecimento como Fortaleza e Juazeiro do Norte, no Ceará, Caruaru em Pernambuco, João Pessoa e Campina Grande, na Paraíba, e Mossoró no Rio Grande do Norte. Além disso, no RIMA são destacadas mais algumas finalidades, como:

- Assegurar safras agrícolas, atividades industriais e o turismo;

- Garantir a permanência da população rural na região, evitando o êxodo rural;

- Proporcionar o aumento das atividades produtivas locais;

- Reduzir os gastos públicos com medidas emergenciais durante os períodos de seca;
- Garantir água para uma infraestrutura da reserva e distribuição já existente como açudes, rios e adutoras.

De acordo com Andrade et al. (2011), as águas serão transpostas através da construção de dois canais artificiais, denominados de Eixo Norte e Eixo Leste, que somam cerca de $477 \mathrm{~km}$ de extensão. Na Fig. 1 é apresentada uma ilustração dos dois eixos. O RIMA relata ainda que, para a operação dos dois eixos e devido às condições topográficas da região entre o rio São Francisco e as bacias receptoras, é prevista a construção de nove estações de bombeamento, quatro túneis, treze aquedutos, nove subestações de 69 kV e 230 kV e $270 \mathrm{~km}$ de linhas de transmissão de energia.

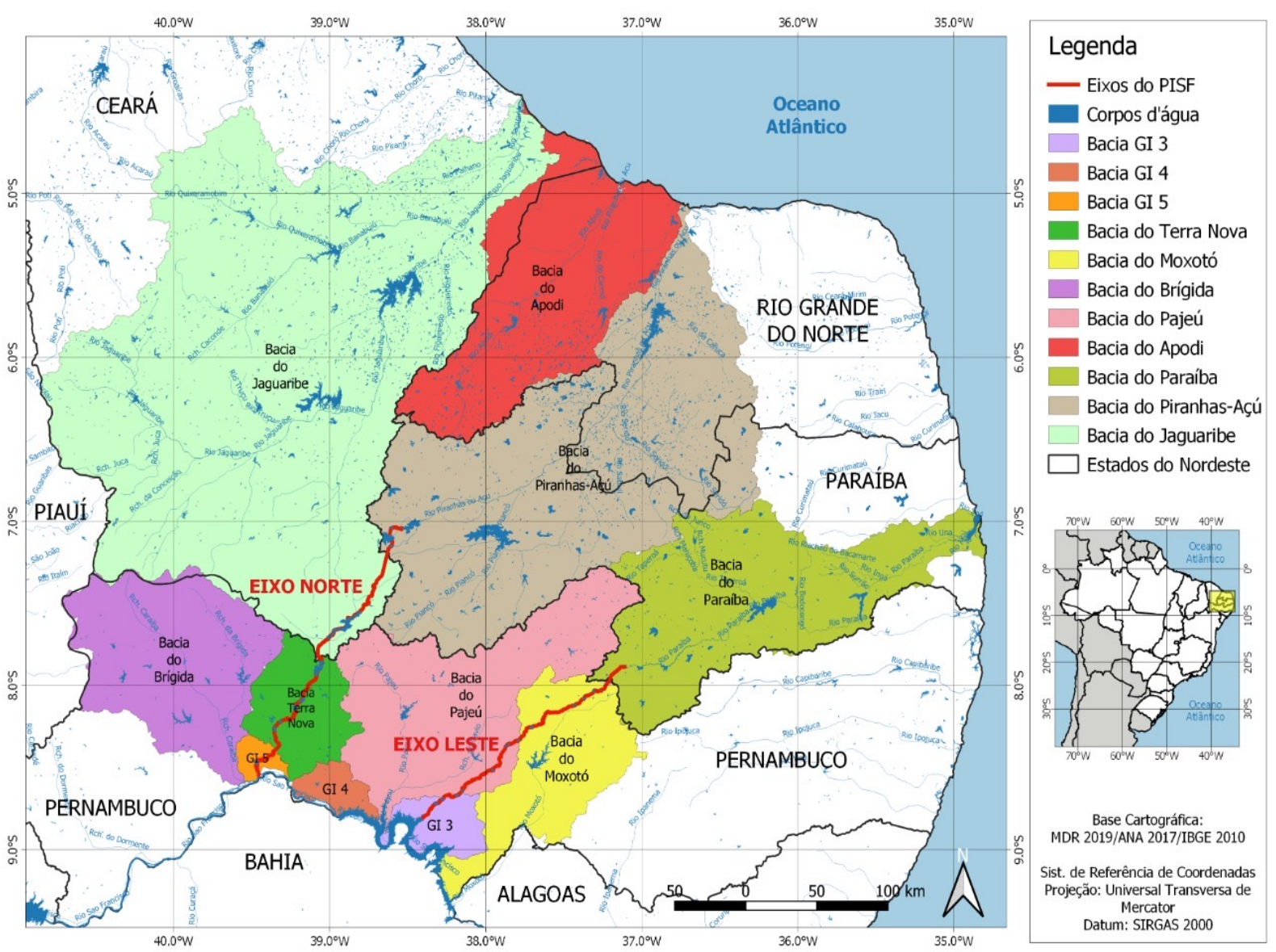

Figura 1 - Representação dos Eixos Norte e Leste integrando a Bacia Fornecedora com as Bacias Receptoras das águas no Nordeste do Brasil. 
O Eixo Leste (Latitude Sul $08^{\circ} 49^{\prime} 37,7^{\prime \prime}$ e Longitude Oeste $38^{\circ} 24^{\prime} 43,3^{\prime \prime}$ ) possui extensão de 217 km e irá conduzir as águas para parte do Sertão e Agreste dos estados de Pernambuco e Paraíba (SEGUNDO NETO e VIANNA, 2016). A água será captada na Barragem de Itaparica, situada no município de Floresta (Pernambuco) e será conduzida ao rio Paraíba (Paraíba). Antes de chegar ao rio Paraíba, a água captada será transportada por ramais conectados ao eixo Leste para as bacias do Pajeú e Moxotó, no Sertão, e para a região Agreste de Pernambuco (CAMELO FILHO, 2005). De acordo com Henkes (2014), a condução das águas para o Agreste de Pernambuco será feita por um ramal de $70 \mathrm{~km}$ de extensão que se conectará à bacia do rio Ipojuca. $\mathrm{O}$ autor ressalta ainda que a capacidade máxima do Eixo Leste é de $28,0 \mathrm{~m}^{3} / \mathrm{s}$; no entanto, esse canal funcionará com vazão contínua de $10,0 \mathrm{~m}^{3} / \mathrm{s}$.

O Eixo Norte (Sul $08^{\circ} 32^{\prime} 41,1^{\prime \prime}$ e Longitude Oeste $\left.39^{\circ} 27^{\prime} 15,2^{\prime \prime}\right)$ possui extensão de $260 \mathrm{~km}$ e conduzirá as águas para o próprio estado de Pernambuco, único estado dos que serão beneficiados que faz parte da bacia do rio São Francisco, Ceará, Paraíba e Rio Grande do Norte (HENKES, 2014). A água será captada nas proximidades da cidade de Cabrobó (Pernambuco) e será conduzida para os rios Salgado e Jaguaribe, no estado do Ceará, Apodi, no estado do Rio Grande do Norte, e Piranhas-Açu, nos estados da Paraíba e Rio Grande do Norte (CAMELO FILHO, 2005). Em Pernambuco, as águas serão conduzidas por ramais conectados ao eixo Norte, que levará a água para os municípios inseridos em três sub-bacias do rio São Francisco. São elas: Brígida, Terra Nova e Pajeú. Todas essas sub-bacias estão situadas no sertão do estado. De acordo com Henkes (2014), para levar água até a região do rio Brígida, situado no Oeste de Pernambuco, será necessário um ramal de $110 \mathrm{~km}$ de extensão. $O$ autor descreve ainda que a capacidade máxima do eixo Norte é de $99,0 \mathrm{~m}^{3} / \mathrm{s}$; no entanto, o canal funcionará com uma vazão contínua de $16,4 \mathrm{~m}^{3} / \mathrm{s}$.
Juntos, os dois eixos de canais serão responsáveis por transferir de forma contínua do rio São Francisco $26,4 \mathrm{~m}^{3} / \mathrm{s}$ e, caso os eixos operem utilizando suas capacidades máximas de transferência de águas, poderão atingir uma vazão de $127,0 \mathrm{~m}^{3} / \mathrm{s}$ (ANDRADE et al., 2011).

Segundo o RIMA, é estabelecido no PISF que em períodos recorrentes de escassez hídrica nas bacias receptoras e de abundância na bacia do rio São Francisco, as vazões transferidas poderão atingir sua capacidade máxima. 0 documento ainda acrescenta que os volumes excedentes transferidos serão armazenados em reservatórios existentes nas bacias receptoras: Atalho e Castanhão, no Ceará; Armando Ribeiro Gonçalves, Santa Cruz e Pau dos Ferros, no Rio Grande do Norte; Engenheiro Ávido e São Gonçalo, na Paraíba; Chapéu e Entre Montes, em Pernambuco.

\section{DESAFIOS DA GESTÃO AMBIENTAL DO PROJETO DE INTEGRAÇÃO DO RIO SÃO FRANCISCO}

Define-se gestão ambiental como o planejamento, administração e monitoramento das atividades econômicas e sociais de modo a utilizar de forma racional os recursos naturais (CATER e WHITE, 2012). Por meio dessa definição, buscouse, a partir de diversas análises bibliográficas e documentais do projeto de integração do rio São Francisco, identificar os principais desafios da gestão ambiental a serem enfrentados na implantação deste empreendimento. Ao todo foram identificados quatro desafios considerados principais da gestão ambiental frente ao projeto:

- Conflito entre o setor energético e o setor de irrigação agrícola;

- Operação do sistema de captação e distribuição da água ao longo dos canais; 
- Impactos não abordados no Estudo de Impacto Ambiental;

- Consequências do armazenamento da água em reservatórios;

\subsection{Conflito entre o setor energético e o setor de irrigação agrícola}

O projeto de integração do rio São Francisco tem por finalidade suplementar principalmente o abastecimento de água para usos e irrigação agrícola na região semiárida do Nordeste Setentrional. A transferência de água ocorrerá por meio da captação desta água a jusante do reservatório da usina hidroelétrica de Sobradinho e a montante do reservatório da usina hidroelétrica Luiz Gonzaga (também conhecida como Itaparica).

Ambos os reservatórios são operados pela Companhia Hidrelétrica do São Francisco (CHESF) e foram criados com intuito de gerar energia e controlar cheias na bacia do São Francisco (MARTINS et al., 2011). De acordo com Henkes (2014), o rio São Francisco representa mais de $90 \%$ de todo o potencial de geração de energia hidrelétrica do Nordeste. Algumas características dos reservatórios podem ser observadas na Tabela 1, conforme descrito por Lerner (2006) e Martins et al., (2011).

Tabela 1 - Características das Barragens entre a área de captação de água pelo projeto de integração do São Francisco.

\begin{tabular}{|c|c|c|c|c|c|}
\hline Reservatório & Inauguração & Região Fisiográfica & $\begin{array}{c}\text { Potência Instalada } \\
\text { (MW) }\end{array}$ & \multicolumn{2}{|c|}{$\begin{array}{c}\text { Volume do Reservatório (m }{ }^{3} \text { ) } \\
\text { Útil }\end{array}$} \\
\hline Sobradinho & 1979 & Médio & 1050 & 34 bilhões \\
\hline Luiz Gonzaga (Itaparica) & 1988 & Sub-Médio & 1500 & 10 bilhões \\
\hline
\end{tabular}

Fonte: Adaptado de Lerner (2006) e Martins et al. (2011).

De acordo com Andrade et al. (2011), para minimizar os impactos negativos do projeto de integração do rio São Francisco na área ambiental e na área de produção de energia hidrelétrica, a transferência de água será limitada a $24,3 \mathrm{~m}^{3} / \mathrm{s}$ e, eventualmente, será aumentada para 114,3 $\mathrm{m}^{3} / \mathrm{s}$ apenas quando o reservatório de Sobradinho estiver com a capacidade de armazenamento $\geq 94 \%$ ou no limite de armazenamento para controle de cheia. Os autores relatam ainda que esse fluxo de transferência altamente variável e limitado de $24,3 \mathrm{~m}^{3} / \mathrm{s}$ ou $114,3 \mathrm{~m}^{3} / \mathrm{s}$ deve ser distribuído e armazenado com intuito de regularizar a utilização nos reservatórios da área atendida.

Diante desse contexto surge uma problemática no projeto proposto, tendo em vista que a acumulação de água no reservatório de Sobradinho depende principalmente das decisões do setor elétrico brasileiro interligado. Os principais focos da transferência de água são atender à demanda por abas- tecimento público e fornecer água suficiente para irrigação agrícola das bacias receptoras. A Política Nacional de Recursos Hídricos do Brasil estabelece que, em situações de escassez, o uso prioritário dos recursos hídricos é o consumo humano e a dessedentação de animais. Nesse sentido, levando em consideração os padrões operacionais do presente, a tomada de decisão se haverá ou não água para usos como a irrigação agrícola nas bacias receptoras do projeto de integração do rio São Francisco e a jusante da barragem de Sobradinho depende das decisões do setor energético do Brasil.

Outro aspecto importante que é estabelecido pela Política Nacional de Recursos Hídricos do Brasil é que a gestão dos recursos hídricos deve sempre proporcionar o uso múltiplo das águas. Portanto, uma forma de solucionar ou ao menos mitigar os efeitos dos conflitos existentes entre os diferentes setores (energético e irrigação agrícola) seria dinamizar a matriz energética do 
Brasil. Lima e Carvalho (2016) em seu trabalho ressaltam a preponderância da energia hidrelétrica na matriz brasileira e defendem o uso de outras fontes renováveis de produção de energia como uma alternativa para reduzir os impactos ambientais negativos oriundos da fonte hídrica. Os autores relatam ainda que o uso de outras fontes renováveis se torna extremamente recomendável nessa conjuntura para reduzir a sobrecarga em relação a um único recurso natural.

O Brasil é um país dotado de recursos renováveis em seu território para produção de energia. Com exceção da energia geotérmica, que possui uma capacidade inexpressiva, as demais fontes renováveis possuem ampla acessibilidade no país como, por exemplo, a eólica, solar (fotovoltaica), biomassa, oceânica e de hidrogênio. Simas e Pacca (2013) defendem a produção de energia por meio de fontes eólicas, tendo em vista que representam uma tecnologia limpa capaz de produzir diversos benefícios ambientais e sociais, sobretudo no que diz respeito à geração de emprego e renda em localidades rurais. Vichi e Mansor (2009) descrevem a aptidão solarimétrica da ordem de $1800 \mathrm{kWh} / \mathrm{m}^{2} / \mathrm{ano}$ a $1950 \mathrm{kWh} / \mathrm{m}^{2} / \mathrm{ano}$ no Brasil, sobretudo no Nordeste, para produção de energia a partir de fontes fotovoltaicas.

Investir nas tecnologias citadas para produção de energia no Nordeste brasileiro, além de ser uma opção para atenuar os conflitos existentes entre o setor de energia e de irrigação agrícola, configura uma melhor forma de aproveitar os recursos naturais, convertendo-os em desenvolvimento social e econômico, fundamental para essa região do país, que possui índices socioeconômicos abaixo da média nacional.

\subsection{Operação do sistema de captação e distribuição da água ao longo dos canais}

Por envolver quatro estados da região Nordeste Setentrional e tendo em vista as grandes distân- cias entre os pontos de captação e os pontos de recepção frente à distribuição da água, a operação do sistema de transferência de água entre as bacias envolvidas apresenta diversas problemáticas (ANDRADE et al., 2011).

A proposta do projeto visa suplementar os usos múltiplos das águas nas bacias receptoras; no entanto, as destinações prioritárias são o abastecimento urbano e a irrigação agrícola (HENKES, 2014). Nesse sentido, é necessário que haja controle na captação e na entrega dos recursos hídricos no que se refere à qualidade e quantidade desses. À medida que os canais avançam dos pontos de captação aos pontos de recepção, ocorre uma demanda em marcha, gerando significativos números de retiradas do recurso. 0 controle eficiente das vazões transportadas ao longo dos canais pode contribuir para a identificação das retiradas ilegais e de possíveis falhas que possam gerar vazamentos, além das perdas por evaporação.

A água é reconhecida como um bem econômico, e por esse motivo a Política Nacional de Recursos Hídricos brasileira tem como um dos seus instrumentos a cobrança pelo uso de seus recursos hídricos.

Esse é outro aspecto que deve ser implementado na operação do sistema ao longo dos canais. A cobrança deve ser feita pelo volume de água recebido, e os valores arrecadados é de onde advêm os recursos financeiros para manter o sistema em operação. Pontes (2018) destaca a importância de fortalecer as organizações institucionais e gerenciais envolvidas a partir de uma estruturação do sistema gestor da União e dos quatros estados envolvidos. Assim, é possível proporcionar o rateio dos custos entre os estados e os pagamentos por meio dos usuários finais para atividades agrícolas e industriais. De acordo com o Comitê de Bacia Hidrográfica do São Francisco (CBSF, 2016), parte do sistema que já está 
em operação, sobretudo o eixo Leste, arrecadou no ano de 2016 cerca de 119 milhões de reais. A mesma fonte relata ainda que o valor arrecadado, além de custear a operação do sistema, vem sendo aplicado em projetos que visam realizar a recuperação ambiental e hidroambiental em diferentes trechos da bacia doSão Francisco. O Plano de Recursos Hídricos da Bacia Hidrográfica do Rio São Francisco estabelece diretrizes e critérios para aplicação de recursos financeiros no processo de revitalização da Bacia do São Francisco. $O$ cumprimento dessas diretrizes e critérios é fundamental para que a gestão ambiental do PISF possa ser considerada adequada.

É importante salientar que, para superar os desafios da operação do sistema listados acima, é necessária tecnologia moderna de instrumentação do empreendimento com leituras automatizadas das vazões de captação, distribuição e entrega nos pontos de utilização, além de um corpo técnico capacitado para aquisição, tratamento e interpretação das informações necessárias que alimentem corretamente a operação do sistema. Nesse sentido torna-se de fundamental importância a implementação do controle dos usos na operação do sistema, conforme estabelecido no plano de recursos hídricos da bacia hidrográfica do rio São Francisco 2016-2025 (CBSF, 2016).

\subsection{Impactos não abordados no Estudo de Impacto Ambiental}

A Política Nacional do Meio Ambiente, na forma da Lei $n^{\circ}$ 6.938/1981, estabelece como um de seus instrumentos a avaliação de impactos ambientais. Devido à importância dessa avaliação para a proteção dos recursos naturais, a Resolução CONAMA no 001/1986 e a Constituição Federal de 1988 corroboraram a aplicação do instrumento, sendo exigido o Estudo de Impacto Ambiental (EIA) e seu respectivo Relatório de Impacto Ambiental (RIMA) para o licenciamento de atividades potencialmente causadoras de significativa degradação ao meio ambiente. Um projeto de transferência de água entre bacias é, notadamente, causador de grandes impactos, que devem, portanto, ser criteriosamente analisados antes de sua implantação.

Ao todo, no RIMA apresentado para licenciamento do PISF, foram identificados 44 impactos, sendo 23 considerados de maior relevância. Desses impactos, 11 são positivos, e 12, negativos. Contudo, efeitos como a salinização do solo, a geração de volume maior de efluentes pelo maior consumo de água e a poluição difusa causada pelas novas áreas de agricultura irrigada são possíveis consequências já verificadas e exemplos de insucesso em transferências de água pelo mundo, que não foram abordadas no estudo.

O fator salinização do solo é um dos mais críticos, sendo introduzido por intervenções humanas por meio da irrigação com água salgada ou outras práticas de irrigação inadequadas, muitas vezes associadas a más condições de drenagem (WANG et al., 2018). As regiões semiáridas, caracterizadas por um clima predominantemente de baixa pluviosidade, altas taxas de evapotranspiração e características do solo que restringem a lixiviação de sal, são pontos de salinização proeminentes (DALIAKOPOULOS et al., 2016). Os fatores citados contribuem para a aceleração do processo de salinização, tornando áreas irrigadas improdutivas em curto espaço de tempo. Sendo assim, caso não haja a adoção de medidas mitigadoras desse impacto, como um maior controle e fiscalização das técnicas de manejo na irrigação, podem ser gerados danos tanto ao meio físico como à população, devido à perda de áreas outrora agricultáveis.

O fato de a maioria dos municípios a serem beneficiados pelo projeto estar situada em áreas onde o índice de acesso ao saneamento básico é dos mais baixos do país também é de grande importância. Segundo o Diagnóstico dos Ser- 
viços de Água e Esgoto de 2017, realizado pela Secretaria Nacional de Saneamento, na região Nordeste os índices de atendimento com rede de água eram de 73,3\% para a população total e $88,8 \%$ para urbana, enquanto em relação à coleta de esgoto obteve-se apenas $26,9 \%$ total e 34,8\% urbana. Em relação ao tratamento dos esgotos, apenas $34,7 \%$ do total gerado na região recebeu tratamento, ao passo que $80,8 \%$ do que foi coletado em rede foi tratado. Com a chegada da água às cidades, haverá grande pressão sobre a infraestrutura urbana que não dispõe de cobertura eficiente em termos de abastecimento de água, coleta e tratamento de esgotos. Portanto, fazem-se necessários investimentos também em obras de saneamento básico, habilitando os municípios a receber as águas do projeto.

Henkes (2014) ressalta, ainda, que o RIMA do PISF, além de deixar de lado questões importantes como as citadas anteriormente, também atribuiu status secundário a algumas outras ao considerá-las "impactos irrelevantes” quando, na verdade, elas têm elevado potencial danoso ou de provocar riscos. São exemplos a redução da energia gerada por usinas ao longo do rio São Francisco e a perda de receitas municipais oriundas da compensação pelo uso dos potenciais hidrelétricos. A queda na geração de energia elétrica afetará a operacionalização do sistema de transporte da água e outras atividades industriais e urbanas. Todavia, tanto a redução de energia elétrica como a compensação financeira foram consideradas impactos irrelevantes.

\subsection{Consequências do armazenamento da água em reservatórios}

Segundo o relatório Conjuntura dos Recursos Hídricos no Brasil 2017, da Agência Nacional de Águas, cerca de $67 \%$ do abastecimento público urbano do Nordeste Setentrional é realizado por água superficial armazenada em açudes, e o PISF tem por objetivo aumentar a garantia da oferta de água nesses reservatórios. De acordo com o RIMA, ao todo serão construídos 24 reservatórios no projeto, variando no tamanho e volume de acumulação. Por estarem localizados de forma superficial, com o espelho de água exposto, os reservatórios estão vulneráveis a agentes que contribuem para a deterioração da qualidade de suas águas. A qualidade de água tem grande impacto na saúde pública e, de modo mais abrangente, na qualidade de vida da população.

As poluições pontual e difusa causadas por ações antrópicas, incidência direta da radiação solar na água causando altas taxas de evaporação, temperaturas altas e baixas amplitudes térmicas (entre $2{ }^{\circ} \mathrm{C}$ e $3^{\circ} \mathrm{C}$ ), a flutuação nos níveis de água devido às estiagens, além dos baixos índices de precipitação e a irregularidade do seu regime são exemplos de fatores que contribuem para o processo de eutrofização (GUNKEL et al., 2015; GUNKEL e SOBRAL, 2013). A eutrofização pode prejudicar a oferta de água para usos múltiplos, além de encarecer os processos de tratamento devido à água de menor qualidade.

O PISF implementou o Programa de Monitoramento da Qualidade da Água e Limnologia para acompanhamento da situação da água nos rios e reservatórios envolvidos no projeto. Sendo parte integrante do Projeto Básico Ambiental do empreendimento, foi elaborado de modo a atender às condicionantes apresentadas na Licença Prévia, emitida pelo Ibama. O programa realiza coletas em regime sazonal, ocorrendo nas estações seca e chuvosa da região. Ao todo, o monitoramento acompanha 86 pontos de coleta distribuídos ao longo dos dois eixos do PISF e dos reservatórios de Sobradinho e Itaparica, levantando dados físico-químicos e biológicos. Esse é um recurso importante; no entanto, devem ser tomadas medidas preventivas para evitar os efeitos negativos aos montantes transferidos do rio São Francisco. Estratégias de gestão do uso do solo nas bacias receptoras que visem reduzir o aporte 
de nutrientes lixiviados pelo escoamento superficial para os reservatórios devem ser implementadas para redução dos níveis de eutrofização, contribuindo para a conservação dos recursos hídricos na região.

Outra implicação importante é a perda de água por evaporação nos reservatórios e canais. $\mathrm{Na}$ região semiárida, a maioria dos cenários de mudanças climáticas é um sinal de que, com o aumento da temperatura, haverá também o aumento da evaporação dos corpos de água e, consequentemente, a redução do fluxo (CIRILO, 2008). Atualmente, várias medidas já foram implementadas ou propostas para reduzir a evaporação em reservatórios de regiões que sofrem com o problema. As mais difundidas incluem dispositivos flutuantes, coberturas de sombreamento suspensas e dispositivos de retardamento do vento (ALVAREZ et al., 2006; ASSOULINE et al., 2011). Portanto, faz-se necessário um estímulo à compreensão da magnitude do fenômeno, que é um componente importante da gestão dos recursos hídricos, como também serem avaliadas alternativas de mitigação que se adequem à realidade local.

\section{CONSIDERAÇÕES FINAIS}

Diante da magnitude da importância de uma melhor distribuição dos recursos hídricos na região Nordeste do Brasil, este estudo buscou avaliar os principais desafios no âmbito da gestão ambiental dos empreendimentos de transferência de água entre bacias por meio do estudo de caso do Projeto de Integração do Rio São Francisco as Bacias Hidrográficas do Nordeste Setentrional - PISF.

A operação do sistema de captação e distribuição da água ao longo dos canais foi identificada como um desafio em virtude da extensão entre a captação e os pontos de recepção desenvolven- do uma demanda em marcha, necessitando de um rigoroso controle de qualidade e quantidade da água a ser transferida, bem como sua cobrança. Para tal, é importante a utilização de tecnologias para instrumentação do empreendimento e de corpo técnico capacitado.

$\mathrm{Na}$ atualidade, os volumes acumulados nos reservatórios de Sobradinho e Itaparica são controlados pelo setor energético, que libera a água a depender da demanda energética. Isso ocasiona variabilidade do volume de água transferido, afetando o setor de irrigação, pois em caso de escassez o recurso hídrico é destinado prioritariamente ao abastecimento urbano e à dessedentação de animais. Uma solução apontada para diminuir esse impacto negativo foi diversificar a matriz energética, investindo em fontes de energia renováveis, como a eólica e a solar, por exemplo, para diminuir a dependência da energia oriunda das hidrelétricas.

Sobre os impactos não previstos no Estudo de Impacto Ambiental, foram detectadas as seguintes possíveis consequências ambientais negativas não abordadas no documento: salinização do solo, poluição difusa causada pelas novas áreas de agricultura irrigada e geração de volume maior de efluentes pelo maior consumo de água. Para mitigar esses efeitos, foram propostas ações como maior controle e fiscalização das técnicas de manejo da irrigação nas áreas agrícolas, além de investimentos em infraestrutura de saneamento básico.

Por se tratar de uma região semiárida, o armazenamento de água em reservatórios foi apontado como um desafio devido à maior susceptibilidade aos efeitos da eutrofização e evaporação. Isso implicaria em redução da oferta hídrica e processo de tratamento mais oneroso da água antes de sua distribuição. Uma medida que poderia ser adotada para prevenir os efeitos da eutrofização seria utilizar estratégias de uso do solo que evi- 
tem a lixiviação de nutrientes para os reservatórios via escoamento superficial. No caso da evaporação, a instalação de dispositivos flutuantes no espelho d'água, coberturas de sombreamento e dispositivos de retardo do vento são soluções que podem mitigar tais efeitos.

Por fim, espera-se que o Projeto de Integração do rio São Francisco promova, além do aumento da disponibilidade hídrica na região semiárida, a conscientização de que é necessário o estudo aprofundado dos impactos ambientais gerados por um empreendimento desta magnitude, e que o mesmo seja integrado ao plano de recursos hídricos da bacia do rio São Francisco, além de seus respectivos desafios de gestão. Tal postura é essencial não só para que se faça o uso correto do grande volume de recursos financeiros despendidos para a construção e operação do projeto, como igualmente para que a sociedade consiga absorver os benefícios gerados, sem que sejam causados danos severos aos demais componentes do meio ambiente onde o empreendimento vem sendo implantado.

\section{CONTRIBUIÇÃO DOS AUTORES}

Conceitualização: Caldas, H.F.M; Oliveira Júnior, A.I. de; Marwell, D.T.B e Sobral, M.C.M. Metodologia: Caldas, H.F.M e Oliveira Júnior, A.I. de. Investigação: Caldas, H.F.M e Oliveira Júnior, A.I. de. Redação: Caldas, H.F.M e Oliveira Júnior, A.I. de; Revisão \& Edição: Caldas, H.F.M; Oliveira Júnior, A.I. de; Marwell, D.T.B e Sobral, M.C.M. Supervisão: Sobral, M.C.M.

\section{REFERÊNCIAS}

ALVAREZ, V.M.; BAILLE, A.; MARTÍNEZ, J.M.; GONZÁLEZ-REAL, M.M. Efficiency of shading materials in reducing evaporation from free water surfaces. Agricultural Water Management. v.84, n.3, p. 229-239, 2006. https://doi.org/10.1016/j.agwat.2006.02.006

ANDRADE, J.G.P.; BARBOSA, P.S.F.; SOUZA, L.C.A.; MAKINO, D.L. Interbasin Water Transfers: The Brazilian Experience and
International Case Comparisons. Water Resour. Manage. v.25, n.8, p.1915-1934, 2011. https://doi-org/10.1007/s11269-0119781-6

ASSOULINE, S.; NARKIS, K.; OR, D. Evaporation suppression from water reservoirs: Efficiency considerations of partial covers. Water Resources Research 47 (7), 2011. https://doi. org/10.1029/2010WR009889

AZEVEDO, L.G.T.; PORTO, R.L.L.; MÉLLO JUNIOR, A.V.; PEREIRA, J.G.; ARROBAS, D.L.P.; NORONHA, L.C.; PEREIRA, L.P. Série Água Brasil - Transferência de águas entre bacias hidrográficas. Brasília: BANCO MUNDIAL, 2005.

BRASIL. Agência Nacional de Águas. Conjuntura dos recursos hídricos no Brasil 2017: relatório pleno/Agência Nacional de Águas. Brasília: ANA, 2017.

BRASIL. Ministério da Integração Nacional. Relatório de Impactos Ambientais do Projeto de Integração do São Francisco. Julho, 2004, 136p.

BRASIL. Ministério do Desenvolvimento Regional. Secretaria Nacional de Saneamento - SNS. Sistema Nacional de Informações sobre Saneamento: Diagnóstico dos Serviços de Água e Esgotos - 2017. Brasília: SNS/MDR, 2019. 226 p.

CAMELO FILHO, J. V. A dinâmica política, econômica e social do rio São Francisco e do seu vale. Revista do Departamento de Geografia. v.17,p. 83-93, 2005. https://doi.org/10.7154/ RDG.2005.0017.0006

CIRILO, J.A. Public water resources policy for the semi-arid region. Estudos Avançados. v.22, n.63, 2008. http://dx.doi.org/10.1590/ S0103-40142008000200005

Comitê de Bacia Hidrográfica do Rio São Francisco (CBHSF), 2016. 2016: 15 anos do CBHSF, 515 anos do Rio São Francisco. 195 p.

DALIAKOPOULOS, I.N.; TSANISA, I.K.; KOUTROULIS, A.; KOURGIALAS, N.N.; VAROUCHAKIS, A.E.; KARATZAS, G.P.; RITSEMAC, C.J. The threat of soil salinity: A European scale review. Sci. Total Environ. v.573, p.727-739, 2016. https://doi. org/10.1016/j.scitotenv.2016.08.177

FORNARELLI, R.; ANTENUCCI, J.P.; MARTI, C.L. Disturbance, diversity and phytoplankton production in a reservoir affected by inter-basin water transfers. Hydrobiologia. v.705, n.1, p. 9-26, 2013. https://doi-org/10.1007/s10750-012-1351-2

GUNKEL, G.; LIMA, D.; SELGE, F.; SOBRAL, M.; CALADO, S. Aquatic ecosystem services of reservoirs in semi-arid areas: sustainability and reservoir management. WIT Trans Ecol Environ. v.197, p.187200, 2015. https://doi.org/10.2495/RMI50171

GUNKEL, G., SOBRAL, M. Re-oligotrophication as a challenge for tropical reservoir management with reference to Itaparica Reservoir, São Francisco, Brazil. Wat Sci Technol. v.67, n.4, p.708714, 2013. https://doi.org/10.2495/RBM130261 
HENKES, S. L. A política, o direito e o desenvolvimento: um estudo sobre a transposição do rio São Francisco. Revista Direito GV, v.10, n.2, p. 497-534, 2014. http://dx.doi.org/10.1590/18082432201421

HE, S.; HIPEL, K.W.; KILGOUR, D.M.Water Diversion Conflicts in China: A Hierarchical Perspective. Water Resour. Manage. v.28, n.7, p. 1823-1837, 2014. https://doi-org/10.1007/s11269-0140550-1

LI, Y.; XIONG, W.; ZHANG, W.; WANG, C.; WANG, P. Life cycle assessment of water supply alternatives in water-receiving areas of the South-to-North Water Diversion Project in China. Water Research. v.89, p.9-19, 2016. https://doi.org/10.1016/j. watres.2015.11.030

LIMA, C. C.; CARVALHO, L. M. DE O. A produção de energia elétrica, a exaustão ambiental da fonte hídrica e a opção proveniente da base eólica renovável. Revista Brasileira de Energias Renováveis. v.5, n.1, p.65-90, 2016. http://dx.doi.org/10.5380/rber. v5i1.43558

MARTINS, D. DE M. F.; CHAGAS, R. M.; MELO NETO, J. DE O.; MELLO JÚNIOR, A. V. Impactos da construção da usina hidrelétrica de Sobradinho no regime de vazões no Baixo São Francisco. Revista Brasileira de Engenharia Agrícola e Ambiental. v.15, n.9, p.1054-1061, 2011. http://dx.doi.org/10.1590/S141543662011001000010

NEVES, C.; CARDOSO, A.P. A experiência internacional com projetos de transposição de águas - lições para o do rio São Francisco. XXIX Encontro Nacional de Engenharia de Produção, Salvador, Brasil, 2009. Anais...

Office of the South-to-North Water Diversion Project Construction Committee, State Council, PRC. The South-to-North Water Diversion Project. Engineering. v.2, n.3, p.265-267, 2016 https:// doi.org/10.1016/J.ENG.2016.03.022

PONTES, N. C. A transposição do rio São Francisco como potencial medida de adaptação às mudanças climáticas. Dissertação (Mestrado em Ciência Ambiental) do Instituto de Energia e Meio Ambiente da Universidade de São Paulo. 114 p. 2018.

RAJABU, K.R.M.; MAHOO, H.F. Challenges of optimal implementation of formal water rights systems for irrigation in the Great Ruaha River Catchment in Tanzania. Agricultural Water Management. v.95, n.9, p.1067-1078, 2008. https://doi. org/10.1016/j.agwat.2008.04.002

SEGUNDO NETO, F. V. A.; VIANNA, P. C. G. Spatial analysis of Works of the São Francisco river integration project - PISF (east branch) in Paraíba state. GeoUERJ. v.28, p.219-241, 2016. https://doi. org/10.12957/geouerj.2016.14536

SIMAS, M.; PACCA, S. Energia eólica, geração de empregos e desenvolvimento sustentável. Estudos Avançados. v.27, n.77, p. 99-115, 2013. http://dx.doi.org/10.1590/S010340142013000100008

US Bureau of Reclamation, 2019. Colorado-Big Thompson Project. https://www.usbr.gov/projects/index.php?id=432 (acesso em 17 de junho de 2019).

VICHI, F. M.; MANSOR, M. T. C. Energia, meio ambiente e economia: o Brasil no contexto mundial. Química Nova. v.32, n.3, p.757-767, 2009. http://dx.doi.org/10.1590/S0100-40422009000300019

WANG, Y.; DENG, C.; LIU, Y.; NIU, Z.; LI, Y. Identifying change in spatial accumulation of soil salinity in an inland river watershed, China. Sci. Total Environ. v.621, p.177-185, 2018. https://doi. org/10.1016/j.scitotenv.2017.11.222

WWF, 2007. Pipedreams? Interbasin water transfers and water shortages. $49 \mathrm{pp}$. http://d2ouvy59p0dg6k.cloudfront.net/ downloads/pipedreams_ibts_final_report_27_june_2007_1.pdf (acesso em 17 de junho de 2019).

ZENG, Q., QIN, L., LI, X. The potential impact of an inter-basin water transfer project on nutrients (nitrogen and phosphorous) and chlorophyll a of the receiving water system. Sci. Total Environ. v.536, p.675-686, 2015. https://doi.org/10.1016/j. scitotenv.2015.07.042

ZHAO, Z.Y.; ZUA, J.; ZILLANTE, G. Transformation of water resource management: a case study of the South-to-North Water Diversion project. Journal of Cleaner Production. v.163, p.136-145, 2017. https://doi.org/10.1016/j.jclepro.2015.08.066

ZHUANG, W. Eco-environmental impact of inter-basin water transfer projects: a review. Environ. Sci. Pollut. Res. v.23, n.13, p.12867-12879, 2016. https://doi-org/10.1007/s11356-016$6854-3$ 